\title{
El imaginario del agua en Rachilde (1860-1953) ${ }^{1}$
}

\section{Lojo-Tizón, $M^{\mathrm{a}}$ del Carmen}

Universidad de Cádiz, carmen.lojo@uca.es

\begin{abstract}
Resumen
Rachilde, prolífica escritora francesa, que desarrolló su carrera literaria durante las últimas décadas del siglo XIX hasta mediados del siglo XX otorga al agua un lugar privilegiado en su producción literaria. El agua constituye un elemento simbólicamente ambiguo pues puede tanto evocar la vida como la muerte. En Rachilde, que manifiesta en su producción un gusto sublime por la ambigüedad en general, su posición respecto del agua es, por el contrario, rotunda e invariable. Presente en sus novelas bajo múltiples formas: estanques, ríos, riachuelos, mar... o también a través de lugares que la evoquen como la bañera, o un pozo, el agua siempre se encuentra asociada a un imaginario de la negatividad. Que sea para Rachilde un elemento ligado a la destrucción y a la muerte tiene una doble motivación: su biografía y la Decadencia, corriente literaria a la que perteneció.
\end{abstract}

Palabras clave: Agua; Decadencia; Destrucción; Negatividad; Rachilde.

\section{Résumé}

Rachilde, prolifique écrivaine française fin de siècle qui a prolongé sa carrière littéraire jusqu'à la première moitié du XXème, attribue à l'eau un espace privilégié dans sa production. En général, l'eau est élément ambigu car elle évoque aussi bien la vie que la mort. Si bien Rachilde montre dans son œuvre un goût sublime à l'égard de l'ambigüité, en ce qui concerne l'eau, la position rachildienne reste claire et invariable. L'eau est présente dans ses romans sous des formes multiples: des étangs, des fleuves, des ruisseaux, la mer..., et aussi à travers quelques lieux qui l'évoquent comme un puits ou une baignoire. Mais sa présence ou évocation est toujours associée à l' imaginaire de la négativité. Que l'eau représente pour Rachilde la mort et la destruction a une double motivation: sa biographie et la Décadence, mouvement littéraire auquel elle appartenait.

Mots-clés: Eau; Décadence; Mort; Destruction; Négativité; Rachilde.

\begin{abstract}
Rachilde, prolific French writer who developed her literary career from the late $19^{\text {th }}$ century to the middle $20^{\text {th }}$, gives a privilege place to the imagery of the water in her literary production. The water forms an ambiguous symbolic element so it may evoke both life and death. In Rachilde, she manifests in her literary production a sublime taste for ambiguity in general; her position in relation with the water is, on the contrary, decisive and constant. It is presented in her novel under multiple forms such as ponds, rivers, streams, seas, etc., and also through places linked with water, like a bath or a well. The water is always linked with a negative kind of imagery. As a destructive and death-relation in Rachildian elements, it has a double motive: her biography and the Decadent movement she belonged to.
\end{abstract}

Keywords: Water; Decadent mouvement; Death; Destruction; Negative; Rachilde.

\footnotetext{
${ }^{1}$ Este artículo ha sido becado por la AFUE
} 
La biografía de Rachilde, escritora francesa que desarrolló su carrera literaria desde finales del siglo XIX hasta mediados del XX, ejerce una influencia fundamental en la producción literaria de la escritora. Tanto el lugar donde nació (el Périgord) como su familia están inmersos en un universo de leyendas y elementos fantásticos que Rachilde no duda en incluir en sus escritos. De entre todos los espacios naturales ligados a su biografía y que Rachilde introduce en sus novelas, la mare aux grenouilles ocupa un lugar sobresaliente. Se trata de un estanque situado muy cerca de la casa donde nació la escritora. Su aspecto tétrico, así como el sonido proveniente del mismo, originado por las ranas que lo habitaban, hacen que Rachilde perciba el estanque como un espacio propicio para el auge de lo fantástico. En su prefacio a À Mort (1886), narra las pesadillas que sufría de manera recurrente durante la adolescencia en las que un ahogado salía de dicho estanque e iba a su encuentro²:

\begin{abstract}
À ce moment de son monologue Rachilde vit une chose monstrueuse s'élever au-dessus de l'eau sombre du mystérieux étang, une sorte de grand, d'immense cadavre blême les bras tendus en avant, la tête ballottant sur les épaules, et l'eau tout autour semblait se soulever d'horreur en grosses vagues muettes. Elle eut un frisson, ouvrit la bouche pour appeler au secours. Ce noyé difforme marchait dans l'eau, il s'éloigna dans la direction des saules, les saules s’écartèrent pour le laisser passer... et une voix qui n’était pas humaine cria à travers la nuit : “Tu ne parleras jamais, jamais” (Finn, 2010: $164)^{3}$.
\end{abstract}

Durante su juventud, la escritora estuvo dos veces a punto de morir en la mare aux grenouilles. Obsesionada por las pesadillas, Rachilde se asoma al estanque para intentar encontrar el origen de su obsesión nocturna y cae en él:

Rachilde, obsédée d’une idée fixe, voulut un jour avoir le cœur net au sujet de ce rêve maudit, elle s’approcha de la mare... et tomba dedans, en criant : Maman ! On fit courir le sot bruit qu'elle s'était suicidée... Mais non... Une simple imagination de jeune fille qui se forme, n'est-ce pas ?... Elle prit un petit rhume, ce fut tout ce qu'elle sut du noyé (id: 165).

En otra ocasión, según confiesa en Les Rageac ${ }^{4}$, su madre ahoga a sus mascotas en el mismo estanque, y la joven Rachilde se lanza, aunque sin éxito, para salvarlas:

Ce n'était pas pour se suicider. Instinctivement, elle voulait les rejoindre, rejoindre ses petits... et ne se doutait pas qu'elle choisissait là un genre de supplice fort en honneur au moyen âge pour les sorcières : on les enfermait dans un sac avec le chat, les rats, les serpents, le hibou, et on balançait le tout au-dessus d'un fleuve.

L'eau de l'étang fit un grand cercle, et, des bulles, crevant à la surface, venues du fond, s'exhalèrent, joyeusement les âmes des petits qui retrouvaient enfin leur mère... (Rachilde, 1921: 217).

Tales vivencias contribuyeron a la formación del imaginario negativo del agua y, en consecuencia, en el desarrollo de una temprana asociación entre el agua y la muerte. La Decadencia, corriente a la que perteneció Rachilde, ayuda sin duda a reforzar dicho imaginario.

Por ello, no es de extrañar que en sus novelas el agua se asocie reiteradamente a la muerte y a la destrucción. Del mismo modo, los estanques que la escritora dibuja en su larga producción, están construidos a imagen de la mare aux grenouilles y recibe todas las connotaciones vinculadas al lugar. En Nono, novela publicada en 1885, la protagonista Renée Fayor, se

\footnotetext{
${ }^{2}$ Edith Silve, en el prefacio de La Tour d'amour de la edición de 1994, insiste en la importancia del agua en el imaginario de Rachilde, cuyo origen se encuentra en la mare aux grenouilles. En el mismo prefacio, Silve hace también referencia a las alucinaciones que sufría la joven Rachilde.

${ }^{3}$ Michael Finn incluye en su publicación Rachilde-Maurice Barrès. Correspondance inédite 1885-1914 un anexo que recoge el prefacio de À Mort.

${ }^{4}$ Les Rageac es una novela de ficción autobiográfica, pues Rachilde compone la trama y los personajes de la misma a partir de su propia biografía.
} 
dirige a caballo al estanque de Combasses, estanque que en la descripción ofrecida por Rachilde adopta los rasgos de la famosa mare aux grenouilles:

\begin{abstract}
Renée mesura la distance. Le chemin très rapide courait droit à l'étang, une mare ténébreuse qu'on apercevait sous les dernières frondaisons. La surface de cette eau paraissait comme une huile. Au-delà, plus rien : le ciel s’éteignait partout. C’était de ce côté de Montpellier, la seule eau profonde que l’on connût, et on avait aidé la nature en adoucissant les bords pour la grossir des pluies d’hiver. Les paysans attachaient à cet étang beaucoup d'histoires fantastiques, car les miasmes des eaux tranquilles et dormantes donnent la fièvre, la fièvre inspiratrice des crimes, de sorte que ces légendes pouvaient être vraies (Rachilde, 1994a: 123).
\end{abstract}

El caballo, al llegar al estanque, se desboca a causa de una picadura de insecto, una reacción exagerada, por lo que más bien parece haber enloquecido, embrujado por el estanque, lugar en el que muere ahogado:

\begin{abstract}
Quelque chose de hideux apparaissait lentement au-dessus de l'eau redevenue agitée, quelque chose qui ressemblait plus à un monstre des légendes paysannes qu'à un animal vivant. Une tête, quelle tête! Avec une crinière raidie de limon saumâtre. Aux naseaux pendaient des joncs pourris aspirés dans des fonds inconnus. Des orbites vitreuses suintaient une boue infecte et l'étoile scintillant à son front orgueilleux avait fait place à un plâtras d'argile. Le cheval hennit. Sa voix tremblotait comme celle des vieux coursiers fourbus qu'on va abattre... il se haussa, essaya de pointer ses oreilles alourdies par la vase... Il voulait répondre au cri de sa maîtresse, puis son pied, sous l'eau, battit un dernier appel, et il se coucha comme un vaisseau submergé ! Il y eut des ondulations molles desquelles émergèrent des grenouilles émeraude, étonnées de ce trouble, et Mélibar [le cheval] plongea et s’engloutit pour l'éternité (id: 126-127).
\end{abstract}

Las muertes por ahogamiento son muy comunes en la obra de Rachilde. La misma suerte que Mélibar, el caballo de Renée, corre Méréra, la perra de Harog y de Ragnacaire en Le meneur de louves (1905) que muere ahogada en un río.

Si bien es cierto que principalmente son los animales quienes mueren en espacios naturales acuáticos (por influencia biográfica de Rachilde) existen también casos de personajes que muestran pensamientos suicidas en relación con dicho espacio, aunque finalmente no se produzca muerte alguna, como ocurre con Madeleine, protagonista de la Princesse des ténèbres (1896): «On y trouve des heures de désolations aiguës où l’on voudrait s’achever, se noyer, mais il ne se présente guère l'occasion d'une belle catastrophe; la mare n'est pas assez profonde pour vous permettre le drame» (Rachilde, 1896: 76).

Aunque el suicidio de personajes no prospere en espacios acuáticos naturales, sí se producen en espacios artificiales que evocan el agua, como el de Lucien Séchard, personaje de L'Animale (1893), que confiesa su intención de quitarse la vida para vengarse de su amante Laure, prometida recientemente a Henri Alban: «Pour que le scandale soit complet, il est nécessaire que je me tue. Il y a un puits derrière l'église, je vais me jeter dans ce puits, j’empoisonnerai l'eau de mon cadavre, on me retirera, et toute la ville saura que je me suis tué en sortant de cette étude» (Rachilde, 1993: 121).

Lucien Séchard cumple su palabra y lleva a cabo la venganza anunciada a través de su muerte en «une eau toute semblable à de l'huile» (id: 124) similar al agua untuosa en la que muere Mélibar, el caballo de Renée Fayor. En Nono, otro de los personajes, Victorien Balthelme, muere en un espacio que evoca el agua, una sala de baños en construcción. Este lugar, en vez de convertirse en espacio de recreo y diversión, se convierte en la tumba de Victorien, y «autour du rocher, l'herbe poussait, aussi drue, aussi épaisse que celle des cimetières» (Rachilde, 1994a: 63). Victorien había sido aplastado por una roca y su cuerpo, ocultado por esta, nunca había sido retirado del lugar. Renée, que pudo haber evitado la muerte, pues vio la roca desprenderse, permitió la muerte de Barthelme, ya que el personaje había venido a visitarla con el fin de continuar la relación que ambos tenían en París y hacerla pública. La sala de baños se convierte también en el lugar donde Renée y su amante Nono tienen encuentros íntimos, y por tanto un espacio en el que el erotismo debiese imperar:

Renée avait les pieds nus dans des mules de satin rouge brodées de turquoises, des mules étroites comme des bibelots d’étagères. 
Le peignoir était très léger et sous la soie, le corps finement sculpté gardait l'humidité du bain qui collait l'étoffe aux plus saillants endroits. Elle se poudrait les bras devant une glace. Sur les dalles traînaient des linges de batiste mouillés, un long drap de flanelle chiffonné et, dans l'eau s’écoulant, on voyait un bracelet de corail. Le lilas éparpillé formait une écume neigeuse aux remous de la vasque à rendre jalouse une Vénus naissante. Cela sentait beaucoup les fleurs, mais davantage la femme et Nono, les narines dilatées, la bouche brûlante, regrettait maintenant d'être là. Il se figurait sa laideur parmi ces beautés, sa gaucherie parmi ces grâces (id: 163-164).

A pesar de que el lugar y el momento propician el erotismo, este nunca prospera debido, en este caso, a los complejos físicos de Nono, y posteriormente por los remordimientos de nuestra particular Venus, pues siempre que intenta mantener relaciones con Nono, el fantasma de Victorien la atormenta.

Además de la estrecha relación entre agua/muerte, los espacios acuáticos están caracterizados según los patrones de la Decadencia. En Le Dessous, novela publicada en 1904, el río del pueblo donde se desarrolla la acción está contaminado, pues en él desemboca el agua que proviene de la red de alcantarillado de París, cuyas consecuencias para el lugar son tierras infértiles de las que emergen olores putrefactos y nauseabundos:

L'endroit était nu, sans un brin d'herbe, s'imbibant par place des petites mares couleur de café. Cela ne sentait pas le fumier ordinaire. Une odeur écœurante, fade, une odeur affreuse, mais rectifiée, s'exhalait de ces bouillies de nègre, la senteur morte de choses déjà tellement mortes qu'elles n’ont plus de nom en aucune langue. Et cette odeur que transmettait la pluie tout en l'atténuant possédait aussi un vague relent de jupes sales. (Rachilde, 1904: 56).

Pero sin duda alguna, la novela de Rachilde en la que el mar obtiene mayor protagonismo es La Tour d'amour (1899). Inspirada por el naufragio de un navío ${ }^{5}$, la novela relata la vida de los dos guardianes del faro de Ar-Men, Jean Maleux y Mathurin Barnabas. En La Tour d'amour (1899), tal y como apunta Edith Silve en el prefacio, el mar no forma parte del decorado de la novela, sino que se convierte en el personaje principal de ésta (Silve, 1994: II-III). Rachilde lleva a cabo una personificación del mar e invierte la asociación tradicional mer/mère, pues en este caso, el mar se convierte en símbolo de la no maternidad. El faro, en representación de lo masculino, y el mar de lo femenino, son personificados hasta el punto de que las embestidas que recibe el faro a causa de las tormentas se perciben como verdaderas relaciones sexuales entre el elemento artificial y el elemento natural. El resultado de dicho acto, bien lejos de generar vida, genera muertes pues el mar, símbolo en nuestro caso de lo antimaterno, provoca el hundimiento de barcos, cuyos ahogados van a parar a los pies del faro:

La mer, symbole de toutes les femmes, ouvre au pied du phare ses énormes cuisses vertes et gainées ; elle soulève ses “jupes jusqu'aux entrailles”, "se lamente comme une épouse trahie”. Jean Maleux la compare à "un sein de femme enragée” puis à “un ventre” et à “une expulseuse d’hommes”. Elle est tour à tour vierge, prostituée, épouse trompée, mère infanticide. Elle porte tous les masques de la femme que lui prête la romancière. Elle est probablement l'expression métaphorique la plus accomplie, dans l'œuvre de Rachilde, des angoisses et des hallucinations de la jeune fille face à sa mère et à la maternité (Silve, 1994: V-VI).

El mar encarna a la mujer en general, y a la Femme fatale en particular. Los guardianes del faro han renunciado al amor. Barnabas, engañado por su mujer, encuentra sosiego con las ahogadas que el mar le ofrece, mujeres muertas ante las que Barnabas se convierte en el único ser dominante (id: VI). Jean Maleux, que muestra su desencanto para con el amor a lo largo de la novela, renuncia a dicho sentimiento. Jean no comparte la necrofilia de Barnabas, pero el desengaño amoroso así como la cierta locura que le origina su vida como guardián de faro, hacen que desarrolle un instinto asesino y mata a una joven. En este momento, se produce una identificación completa entre la joven muerta y el mar pues el protagonista

\footnotetext{
${ }^{5}$ Según indica Edith Silve en el prefacio de la Tour d'amour, Rachilde se inspira del naufragio del navío Drummond-Castle: "La romancière se contentera de transformer, par simple alitération, le Drummond-Castle, en Dermond-Nestle [nombre del barco que naufraga en La Tour d'amour], qui, lui aussi, arrive du cap de Bonne-Espérance” (Silve, 1994: IV).
} 
declara, tras matar a la joven, haber matado al mar: «j’ai tué la mer» (Rachilde, 1994b: 153). El asesinato del mar se convierte en símbolo del rechazo al amor, a la mujer y a la madre (Silve, 1994: XI).

En conclusión, la presencia del universo acuático es fundamental en la obra de Rachilde. Como cualquier elemento natural, el agua es considerada como una amenaza, pues lejos de ser un refugio para el ser humano, para aquellos que cultivaron la corriente decadente, la naturaleza es el enemigo. La Decadencia aboga por el artificio, así que todo lo natural se rechaza y desprecia. En el caso de Rachilde, dicho rechazo se acentúa debido a su propia experiencia y por ello, de entre todos los elementos naturales que forman parte de su producción literaria, el universo acuático siempre conforma un espacio adverso.

\section{Referencias bibliográficas}

DAuphine, Claude (1985). Rachilde, femme de lettres 1900, Périgueux: Pierre Fanlac.

- (1991). Rachilde, París: Mercure de France.

DAvid, André (1924). Rachilde, Homme de Lettres, París: Éditions de la Nouvelle Revue Critique.

FInN, Michael (2002). Rachilde-Maurice Barrès: Correspondance inédite, 1885-1914. Brest: Centre d’Etude des Correspondances et Journaux intimes des XIX et XX ${ }^{\mathrm{e}}$ siècles, 2010. Disponible en $<$ https://www.univ-brest.fr/digitalAssets/23/23123_TEXTEFINAL-RACHILDE-BARRES.pdf $>$ [Consultado el 5/05/2013].

Justel, Pablo (2016). «Espace et langage: La Tour d'amour de Rachilde et la Tour de Babel» en Çédille, revista de estudios franceses

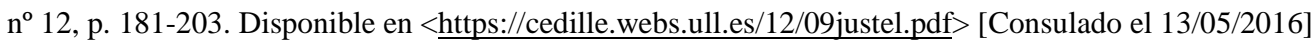

RACHILDE (1904). Le Dessous, París: Mercure de France.

— (1905). Le Meneur de Louves, París: Société du Mercure de France.

— (1921). Les Rageac, París: Ernest Flammarion.

- (1947). Quand j'étais jeune, París: Mercure de France.

— (1993). L’Animale, París: Mercure de France, (1ª ed. 1893).

- (1994a). Nono, París: Mercure de France, (1 $1^{\mathrm{a}}$ ed. 1885).

- (1994b). La Tour d'amour, París: Mercure de France, (1ª ed. 1899).

SILVE, Édith (1994). Prefacio a La Tour d'amour de Rachilde, p. I-XVII, París: Mercure de France. 